INOVAÇÃO SOCIAL

Empreendedorismo Social 


\section{SOBRE OS AUTORES}

Daniela de Oliveira Massad | danielamassad@hotmail.com

Lattes: http://lattes.cnpq.br/9453624212815262

Mestranda em Engenharia e Gestão do Conhecimento pela Universidade Federal de Santa Catarina (UFSC). Graduada em Engenharia de Produção com ênfase em Qualidade Química pela Universidade do Estado do Rio de Janeiro (UERJ) (2003). Técnica em Química pela Escola Técnica Federal do Rio de Janeiro (1998), atual Instituto Federal do Rio de Janeiro. Membro do Grupo de Pesquisa Inovação em Ciência e Tecnologia/UFSC, certificado pelo Conselho Nacional de Desenvolvimento Científico e Tecnológico (CNPq).

Ivana Maria Fossari | ivanafossari@hotmail.com

Lattes: http://lattes.cnpq.br/4650044519212315

Doutoranda em Engenharia e Gestão do Conhecimento pela UFSC. Mestre em Educação pela UFSC (1999).

Graduada em Letras - Licenciatura de $1^{\circ}$ Grau com Habilitação Português-Inglês (1979) e em Enfermagem (1983), ambos pela UFSC. Membro do Grupo de Pesquisa Inovação em Ciência e Tecnologia/UFSC, certificado pelo CNPq.

Édis Mafra Lapolli | edismafra@gmail.com

Lattes: http://lattes.cnpq.br/8977816806473448

Doutora e mestre em Engenharia de Produção pela UFSC com pós-doutorado em Sistemas de Informação pela Université de Montpellier II (França). Engenheira civil, professora do Programa de Pós-Graduação em Engenharia e Gestão do Conhecimento e coordenadora (desde março de 2017) da área de Gestão do Conhecimento da UFSC, consultora organizacional nas áreas de gestão de pessoas, desenvolvimento do potencial humano e empreendedorismo e coordenadora de projetos da Editora Pandion. Líder do Grupo de Pesquisa Inovação em Ciência e Tecnologia/UFSC e do Grupo de Pesquisa Geoengenharia/ UFSC, ambos certificados pelo CNPq. 

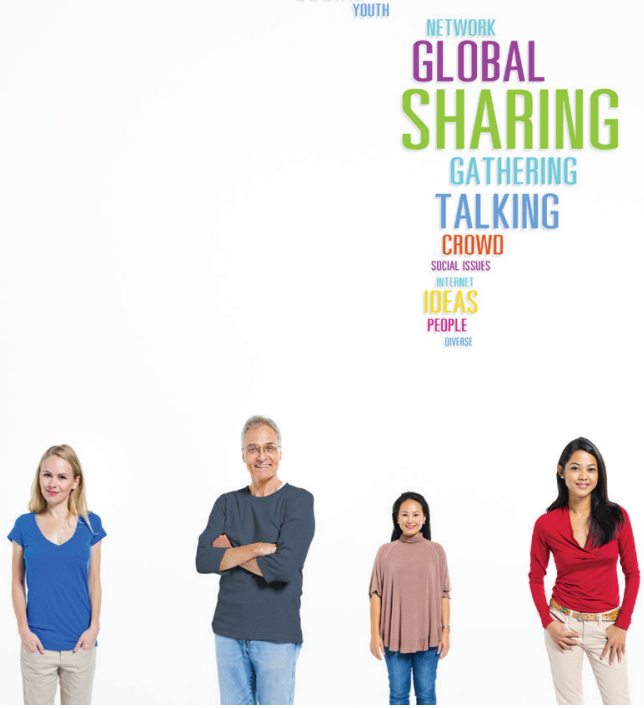

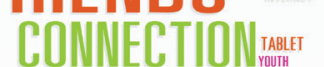

SOCIAL ISSUES
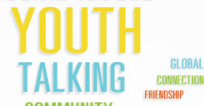

COMMUNITY

ETHNIC
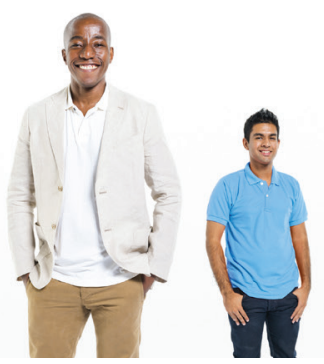
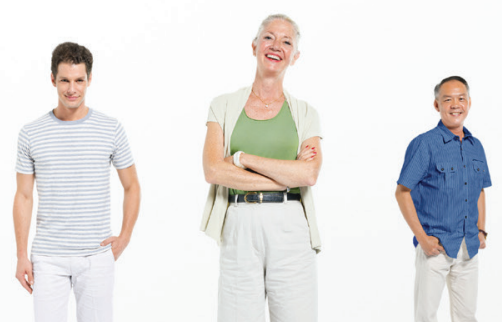

\title{
Inovação social e empreendedorismo social: uma revisão integrativa
}

\author{
Social innovation and social entrepreneurship: \\ a integrative review
}

Daniela de Oliveira Massad, Ivana Maria Fossari, Édis Mafra Lapolli

\section{Resumo}

Os esforços em resolver problemas sociais têm tornado temas como inovação social e empreendedorismo social cada vez mais conhecidos. Com o objetivo de realizar um levantamento teórico sobre os dois construtos - inovação social e empreendedorismo social -, este artigo traz uma revisão integrativa de artigos publicados na base de dados Scopus nos últimos anos. Por meio de análise bibliométrica, observou-se que os estudos sobre o tema estão em evidência nos últimos anos e que a maioria deles possui origem em países de língua inglesa como Estados Unidos e Reino Unido. Pela avaliação dos conteúdos, constatou-se que alguns artigos abordam os dois construtos de forma diferente, porém para estudos atuais podem ser considerados assuntos complementares. A partir deste recorte da produção científica recente, foi possível verificar a importância e a necessidade do desenvolvimento de estudos no tema proposto.

\section{Abstract}

Efforts to solve social problems have made issues such as social innovation and social entrepreneurship increasingly well known. With the objective of carrying out a theoretical survey on the two constructs - social innovation and social entrepreneurship - this article brings an integrative review of articles published in the Scopus database in recent years. Through bibliometric analysis it has been observed that studies on the subject have been in evidence in recent years and that most of them originate in English-speaking countries such as the United States and United Kingdom. Due to the evaluation of the contents, it was found that some articles approach the two constructs in a different way, but for current studies they can be considered complementary subjects. From this cut of the recent scientific production it was possible to verify the importance and necessity of the development of studies in the proposed theme.. 

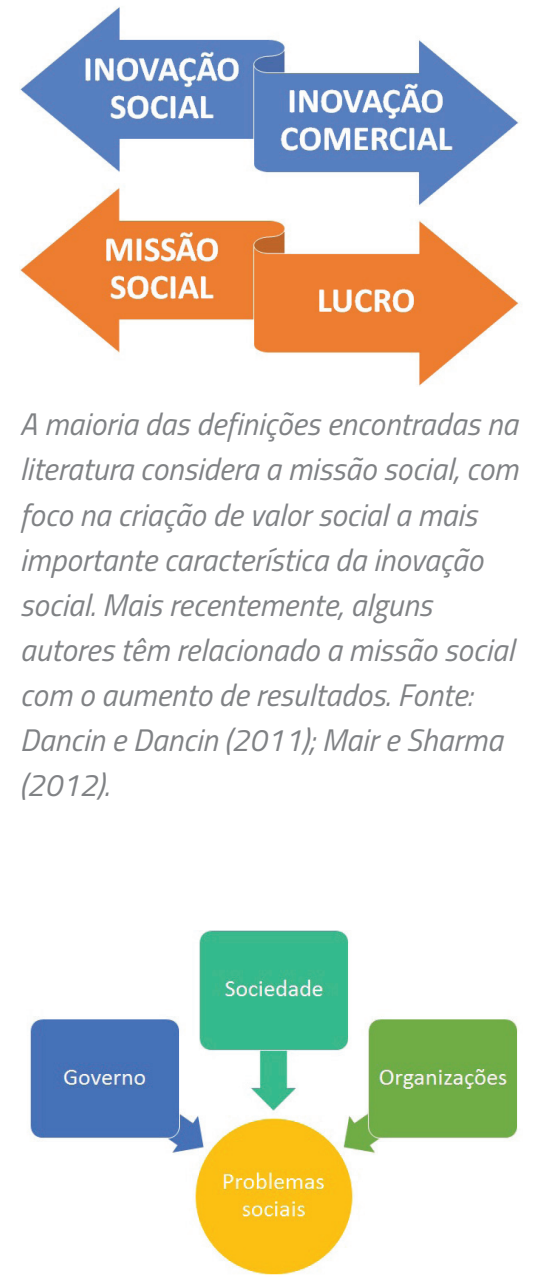

Atores da inovação social.

Fonte: Elaborada pelas autoras com base na pesquisa realizada.

\section{INTRODUÇÃO}

Os temas inovação social e empreendedorismo social têm despertado crescente interesse por parte de pesquisadores e empresários que buscam amenizar os problemas sociais. Desilusões com modelos de negócios com fins lucrativos têm motivado iniciativas de empreendimentos sociais em diversas áreas. Portanto, levantamentos exploratórios sobre o tema são pertinentes para analisar a produção científica e visualizar como ela tem se orientado.

A sobrevivência de muitas empresas depende do quão inovadoras elas são para se tornarem mais competitivas. Logo, o termo inovação está totalmente ligado à criação de novos conhecimentos e ao ganho de competitividade (URIARTE, 2008). Inovar também está relacionado ao desenvolvimento econômico, pois a inovação é o fator mais relevante na nova economia mundial (PORTER, 1980).

O Manual de Oslo, em sua terceira edição, define inovação como "a implementação de um produto (bem ou serviço) novo ou significativamente melhorado, ou um processo, ou um novo método de marketing, ou um novo método organizacional nas práticas de negócios, na organização do local de trabalho ou nas relações externas" (OCDE, 2005, p. 55).

Inovações sociais podem ser definidas como novas ideias, atividades e serviços inovadores que surgem com o objetivo de satisfazer a necessidades sociais (MULGAN; TUCKER; ALI; SANDERS, 2007). 0 empreendedor social seria, então, um agente da inovação social (JULIANI, 2015).

Muito se discute hoje em dia sobre a capacidade das instituições governamentais de solucionar os problemas sociais. Pela ausência de resposta a essa questão é que surgem, por parte da sociedade, iniciativas de atividades ou empreendimentos totalmente voltados para atender a necessidades sociais. Tem crescido também o número de empresas criadas com o objetivo de auxiliar financeiramente grupos que organizem práticas inovadoras para resolver problemas sociais.

Apesar de se encontrar extensa literatura sobre empreendedorismo comercial e empreendedorismo social, existem pontos que geram discussões intensas e, em muitos casos, os assuntos são tratados de forma independente, 
dificultando o desenvolvimento de uma base teórica robusta sobre o campo (AUSTIN; STEVENSON; WEI-SKILLERN, 2006). Nesse sentido, este trabalho se propõe a realizar uma revisão integrativa dos assuntos inovação social e empreendedorismo social, ampliando, assim, a compreensão conceitual sobre eles, e descrever as características semelhantes e diferentes a partir de estudos encontrados na literatura. Assim, a questão de pesquisa que se pretende responder com este estudo é: qual o estado da produção bibliográfica sobre a inovação social e o empreendedorismo social?

Inovação social e empreendedorismo social são temas abrangentes que envolvem diversas áreas de pesquisa, como Ciências Sociais, Economia, Engenharia Ambiental, Medicina, Psicologia, dentre outras. Muitas pesquisas têm sido realizadas sobre esses temas agregando diversos conhecimentos de interesse. 0 presente artigo tem por objetivo realizar levantamento teórico sobre inovação social e empreendedorismo social, demonstrando as semelhanças e diferenças existentes, analisar as lacunas existentes entre os estudos encontrados na literatura e identificar oportunidades de pesquisas. Para tal, estruturou-se o trabalho da seguinte forma: (1) Introdução; (2) Procedimentos metodológicos; (3) Resultados e discussões; e (4) Considerações finais.

\section{METODOLOGIA}

A revisão integrativa é um método de pesquisa utilizado na prática baseada em evidências. É um método específico de revisão da literatura que inclui estudos teóricos ou experimentais sobre um tema particular. O objetivo da revisão integrativa é analisar pesquisas relevantes sobre um tema, possibilitando a síntese do estado da arte deste, e também apontar lacunas do conhecimento que podem ser preenchidas por novos estudos (POLIT; BECK, 2006).

Existe, na literatura, uma variedade de procedimentos metodológicos de diferentes autores para definir as etapas da revisão integrativa, no entanto, para o desenvolvimento deste estudo, optou-se pela proposta de Botelho, Cunha e Macedo (2011), que percorre as seguintes etapas:

Para um entendimento abrangente do assunto, realizou-se a pesquisa dos construtos em inglês "social innovat*" e "social entrepreneur*" na base de dados Scopus, pois se trata de uma base internacional multidisciplinar 
que permite levantamentos por palavras-chave e título do artigo. Utilizouse as aspas para que não fossem levantadas publicações sobre cada termo individualmente e o asterisco para que fossem considerados todos os caracteres possíveis após a última letra, realizando-se um estudo mais abrangente. Por exemplo, para "social innovat*" podemos ter "social innovation" (inovação social) ou "social innovator" (inovador social), e para "social entrepreneur*" é possível encontrar "social entrepreneurship" (empreendedorismo social) ou "social entrepreneur" (empreendedor social).

\begin{tabular}{|c|l|}
\hline 1 & Identificação do tema e seleção da questão de pesquisa \\
\hline 2 & Estabelecimento dos critérios de exclusão e inclusão \\
\hline 3 & Identificação dos estudos pré-selecionados e selecionados \\
\hline 4 & Categorização dos estudos selecionados \\
\hline 5 & Análise e interpretação dos resultados \\
\hline 6 & Apresentação da revisão/síntese do conhecimento \\
\hline
\end{tabular}

No tópico seguinte, serão apresentados os resultados da busca na literatura e do tratamento dos dados realizado nos estudos selecionados, com a apresentação de quadros e gráficos e da discussão do conhecimento dos conceitos de inovação social e empreendedorismo social.

\section{CRITÉRIOS UTILIZADOS E ESTUDOS SELECIONADOS}

A partir do levantamento inicial na base de dados Scopus dos construtos "social innovat*" ou "social entrepreneur*" nos títulos, resumos e palavras-chave, surgiram 2.626 documentos. Realizando-se 0 refinamento da busca para os artigos que contenham os construtos em seus títulos, obtêm-se os resultados do Quadro 1.

Quadro 1 Documentos contendo os construtos no título.

\begin{tabular}{|l|c|}
\hline Construto & Documentos \\
\hline "social entrepreneur*" & 671 \\
\hline "social innovat*" & 527 \\
\hline "social entrepreneur*" e "social innovat*" & 16 \\
\hline
\end{tabular}

Fonte: Elaborado pelas autoras (agosto/2016). 
Assim, encontrou-se um total de 1.182 documentos sobre os assuntos pesquisados, com a retirada dos repetidos. 0 primeiro documento sobre inovação social data de 1966 (GARVEY; GRIFFITH, 1966). Após este artigo, outra publicação surgiu apenas cinco anos depois, em 1971 (BROADY, 1971). Já o termo "empreendedor social" aparece pela primeira vez no trabalho de Lessem (1978). 0 gráfico a seguir demonstra como o número de publicações sobre o tema em estudo teve um expressivo crescimento nos últimos anos.

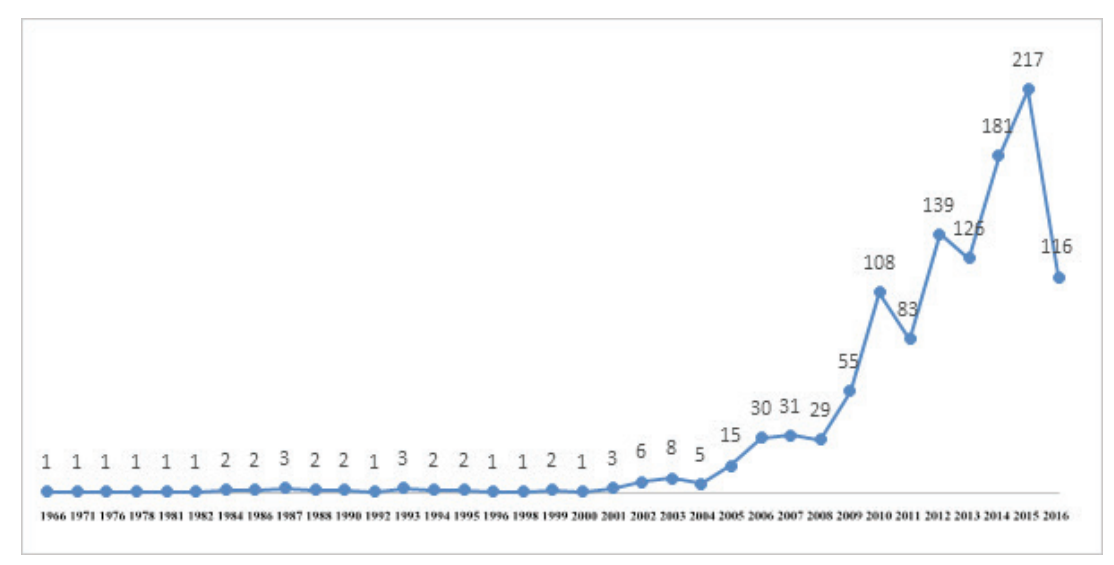

Publicações por ano dos construtos na base de dados Scopus.

Fonte: Elaborada pelas autoras (agosto/2016).

Restringindo-se a pesquisa apenas a documentos publicados nos últimos cinco anos (desde 2011), nas línguas inglesa, espanhola e portuguesa, obteve-se um total de 847 artigos. Nesse grupo, observouse uma maior concentração de pesquisas nos Estados Unidos, com 206 estudos, seguidos pelo Reino Unido, com 100, e por Espanha e Canadá, com 66 e 57 documentos respectivamente. É importante ressaltar que o Brasil apontou com 24 estudos, juntamente com Índia e Japão, demonstrando a ampla preocupação com o tema, inclusive nos países em desenvolvimento.

Do grupo de 847 documentos, 14 continham os dois construtos no título, "social entrepreneur*" e "social innovat*", sendo que um deles se tratava, na verdade, de uma errata de um dos artigos. Com base na leitura do resumo dos 13 documentos restantes e da disponibilidade de acesso na base Scopus, chegou-se a um total de 7 documentos. Além destes, foram considerados os 5 artigos mais citados que continham em seu título apenas o construto "social entrepreneur*". Dentre os 15 artigos 
mais citados contendo apenas o termo "social innovat*", observou-se que 4 figuravam dentre os 7 documentos selecionados que continham também o construto "social entrepreneur*". A partir da leitura dos resumos dos 11 artigos restantes, selecionaram-se mais 4 artigos para compor o conjunto de documentos desta revisão integrativa, pois contribuiriam positivamente para a análise. Dessa forma, utilizou-se a amostra final de 16 estudos demonstrada no Quadro 2, que também apresenta a sintese de cada uma das publicações. Todos os artigos são publicações de journals internacionais, exceto o último documento do quadro, que corresponde a um capítulo de livro.

Quadro 2 Estudos incluídos na revisão integrativa.

\begin{tabular}{|c|c|c|}
\hline Autores (Ano) & Título do artigo & Sintese \\
\hline $\begin{array}{l}\text { Dacin, M. T.; } \\
\text { Dacin, P. A.; } \\
\text { Tracey, P. } \\
\text { (2011) }\end{array}$ & $\begin{array}{l}\text { Social } \\
\text { entrepreneurship: a } \\
\text { critique and future } \\
\text { directions }\end{array}$ & $\begin{array}{l}\text { Analisa o empreendedorismo } \\
\text { social como área de investigação } \\
\text { acadêmica e sugere caminhos } \\
\text { para a construção de teorias } \\
\text { sobre o tema }\end{array}$ \\
\hline $\begin{array}{l}\text { Santos, F. M. } \\
(2012)\end{array}$ & $\begin{array}{l}\text { A positive } \\
\text { theory of social } \\
\text { entrepreneurship }\end{array}$ & $\begin{array}{l}\text { Explica o papel distintivo do } \\
\text { empreendedorismo social na } \\
\text { sociedade moderna e busca } \\
\text { promover o avanço do campo } \\
\text { acadêmico sobre o assunto }\end{array}$ \\
\hline $\begin{array}{l}\text { Miller, T. } \\
\text { L.; Grimes } \\
\text { M. G.; } \\
\text { McMullen, J. } \\
\text { S.; Vogus, T. } \\
\text { J. (2012) }\end{array}$ & $\begin{array}{l}\text { Venturing for others } \\
\text { with heart and head: } \\
\text { how compassion } \\
\text { encourages social } \\
\text { entrepreneurship } \\
\text { challenges }\end{array}$ & $\begin{array}{l}\text { Avalia a correlação } \\
\text { entre a compaixão e as } \\
\text { motivações tradicionais do } \\
\text { empreendedorismo social }\end{array}$ \\
\hline $\begin{array}{l}\text { Moore, M.- } \\
\text { L.; Westley, } \\
\text { W. (2011) }\end{array}$ & $\begin{array}{l}\text { Surmountable } \\
\text { chasms networks and } \\
\text { social innovation for } \\
\text { resilient systems }\end{array}$ & $\begin{array}{l}\text { Analisa como as redes } \\
\text { sociais contribuem para a } \\
\text { inovação social e como o } \\
\text { empreendedorismo institucional } \\
\text { pode melhorar o desempenho } \\
\text { das redes }\end{array}$ \\
\hline $\begin{array}{l}\text { Young, H. P. } \\
\text { (2011) }\end{array}$ & $\begin{array}{l}\text { The dynamics of } \\
\text { social innovation }\end{array}$ & $\begin{array}{l}\text { Propõe um modelo da dinâmica } \\
\text { da inovação social avaliando os } \\
\text { fatores que aceleram a sua difusão }\end{array}$ \\
\hline
\end{tabular}




\begin{tabular}{|c|c|c|}
\hline Autores (Ano) & Título do artigo & Sintese \\
\hline $\begin{array}{l}\text { Bacq, S.; } \\
\text { Janssen, F. } \\
(2011)\end{array}$ & $\begin{array}{l}\text { The multiple } \\
\text { faces of social } \\
\text { entrepreneurship: a } \\
\text { review of definitional } \\
\text { issues based on } \\
\text { geographical and } \\
\text { thematic criteria }\end{array}$ & $\begin{array}{l}\text { Avalia as diferenças entre as } \\
\text { definições americana e europeia } \\
\text { de empreendedorismo social e } \\
\text { discute implicações para futuras } \\
\text { pesquisas }\end{array}$ \\
\hline $\begin{array}{l}\text { Mair, J.; } \\
\text { Battilana, J.; } \\
\text { Cardenas, J. } \\
\text { (2012) }\end{array}$ & $\begin{array}{l}\text { Organizing for society: } \\
\text { a typology of social } \\
\text { entrepreneuring } \\
\text { models }\end{array}$ & $\begin{array}{l}\text { Estuda a tipologia dos modelos } \\
\text { empreendedores existentes no } \\
\text { campo do empreendedorismo } \\
\text { social }\end{array}$ \\
\hline $\begin{array}{l}\text { Cajaiba- } \\
\text {-Santana, G. } \\
(2014)\end{array}$ & $\begin{array}{l}\text { Social innovation: } \\
\text { moving the field } \\
\text { forward. A conceptual } \\
\text { framework }\end{array}$ & $\begin{array}{l}\text { Apresenta um quadro conceitual } \\
\text { para investigar a inovação } \\
\text { social como motor de mudança } \\
\text { social, com base em teorias } \\
\text { institucionais e estruturalistas }\end{array}$ \\
\hline $\begin{array}{l}\text { Witkamp, } \\
\text { M. J.; Raven, } \\
\text { R. P. J. M.; } \\
\text { Royakkers, L. } \\
\text { M. M. (2011) }\end{array}$ & $\begin{array}{l}\text { Strategic niche } \\
\text { management of } \\
\text { social innovation: } \\
\text { the case of social } \\
\text { entrepreneurship }\end{array}$ & $\begin{array}{l}\text { Avalia como a ferramenta gestão } \\
\text { estratégica de nicho pode ser } \\
\text { utilizada para analisar a inovação } \\
\text { social }\end{array}$ \\
\hline $\begin{array}{l}\text { Maclean, M.; } \\
\text { Harvey, C.; } \\
\text { Gordon, J. } \\
\text { (2013) }\end{array}$ & $\begin{array}{l}\text { Social } \\
\text { innovation, social } \\
\text { entrepreneurship } \\
\text { and the practice } \\
\text { of contemporary } \\
\text { entrepreneurial } \\
\text { philanthropy }\end{array}$ & $\begin{array}{l}\text { Estudo de caso sobre o processo } \\
\text { de inovação social desenvolvido } \\
\text { por uma fundação comunitária } \\
\text { no nordeste da Inglaterra e suas } \\
\text { contribuições para a teoria e a } \\
\text { prática da filantropia empresarial }\end{array}$ \\
\hline $\begin{array}{l}\text { Chalmers, D. } \\
\text { (2013) }\end{array}$ & $\begin{array}{l}\text { Social innovation: } \\
\text { an exploration of } \\
\text { the barriers faced } \\
\text { by innovating } \\
\text { organizations in the } \\
\text { social economy }\end{array}$ & $\begin{array}{l}\text { Analisa barreiras para um } \\
\text { comportamento socialmente } \\
\text { inovador e propõe um modelo } \\
\text { de inovação social "aberta" }\end{array}$ \\
\hline
\end{tabular}




\begin{tabular}{|c|c|c|}
\hline Autores (Ano) & Título do artigo & Síntese \\
\hline $\begin{array}{l}\text { Shaw, E.; } \\
\text { De Bruin, A. } \\
\text { (2013) }\end{array}$ & $\begin{array}{l}\text { Reconsidering } \\
\text { capitalism: the } \\
\text { promise of social } \\
\text { innovation and social } \\
\text { entrepreneurship? }\end{array}$ & $\begin{array}{l}\text { Propõe uma agenda de } \\
\text { pesquisas futuras para o } \\
\text { avanço do conhecimento } \\
\text { sobre a inovação social e o } \\
\text { empreendedorismo social }\end{array}$ \\
\hline $\begin{array}{l}\text { Smith, I. H.; } \\
\text { Woodworth, } \\
\text { W. P. (2012) }\end{array}$ & $\begin{array}{l}\text { Developing social } \\
\text { entrepreneurs and } \\
\text { social innovators: } \\
\text { a social identity } \\
\text { and self-efficacy } \\
\text { approach }\end{array}$ & $\begin{array}{l}\text { Apresenta uma abordagem de } \\
\text { identidade social e autoeficácia } \\
\text { e identifica desafios e formas } \\
\text { de superação para o ensino } \\
\text { do empreendedorismo e da } \\
\text { inovação social em ambientes } \\
\text { universitários }\end{array}$ \\
\hline $\begin{array}{l}\text { Phillips, } \\
\text { W.; Lee, H.; } \\
\text { Ghobadian, } \\
\text { A.; O'Regan, } \\
\text { N.; James, P. } \\
\text { (2015) }\end{array}$ & $\begin{array}{l}\text { Social innovation } \\
\text { and social } \\
\text { entrepreneurship: a } \\
\text { systematic review }\end{array}$ & $\begin{array}{l}\text { Estuda a relação entre as } \\
\text { pesquisas em inovação e } \\
\text { empreendedorismo social e } \\
\text { propõe uma abordagem de } \\
\text { "sistemas de inovação" para } \\
\text { estudos futuros }\end{array}$ \\
\hline $\begin{array}{l}\text { Nandan, } \\
\text { M.; London, } \\
\text { M.; Bent- } \\
\text { Goodley, T. } \\
\text { (2015) }\end{array}$ & $\begin{array}{l}\text { Social workers } \\
\text { as social change } \\
\text { agents: social } \\
\text { innovation, social } \\
\text { intrapreneurship, } \\
\text { and social } \\
\text { entrepreneurship }\end{array}$ & $\begin{array}{l}\text { Estuda as práticas de inovação } \\
\text { social, empreendedorismo } \\
\text { social e intraempreendedorismo } \\
\text { social realizadas por assistentes } \\
\text { sociais }\end{array}$ \\
\hline $\begin{array}{l}\text { Cunha, J.; } \\
\text { Benneworth, } \\
\text { P.; Oliveira, } \\
\text { P. (2015) }\end{array}$ & $\begin{array}{l}\text { Social } \\
\text { entrepreneurship and } \\
\text { social innovation: a } \\
\text { conceptual distinction }\end{array}$ & $\begin{array}{l}\text { Apresenta as definições de } \\
\text { empreendedorismo social } \\
\text { e inovação social e discute } \\
\text { o papel das instituições de } \\
\text { ensino superior para promover } \\
\text { iniciativas no campo }\end{array}$ \\
\hline
\end{tabular}

Fonte: Elaborado pelas autoras.

A próxima seção fará a discussão conceitual dos construtos empreendedorismo social e inovação social, realizando a análise de semelhanças e diferenças entre eles e possivveis lacunas na literatura. 


\section{EMPREENDEDORISMO SOCIAL E INOVAÇÃO SOCIAL}

Apesar de haver semelhanças entre as definições e os diversos componentes e facilitadores da inovação social e do empreendedorismo social, existem também diversidades de abordagens entre as escolas de pensamento dessas atividades. Nos Estados Unidos, existem duas escolas que estudam o fenômeno a partir de perspectivas diferentes. A Social Innovation School destaca a importância do empreendedor social e suas características e o considera figura central do empreendedorismo social, enquanto para a Social Enterprise School a figura do empreendedor social possui um papel secundário. Além disso, a Social Enterprise School aceita algum tipo de distribuição de lucro, mas possui restrições a fim de proteger a primazia da missão social, já a Social Innovation School não apresenta restrições quanto a sua existência (BACQ; JANSSEN, 2011).

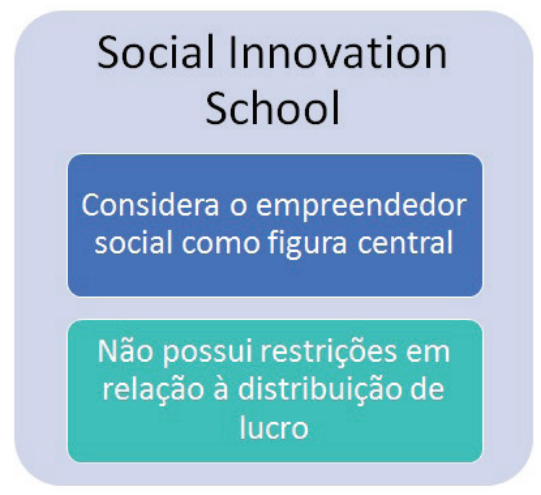

\section{Social Enterprise School}

O empreendedor social

tem papel secundário

A distribuição de lucro é limitada a fim de proteger a primazia da missão social

Algumas diferenças entre as escolas de pensamento americanas. Fonte: Elaborada pelas autoras, com base na pesquisa realizada.

Na prática, existem diferentes modelos empreendedores no campo do empreendedorismo social. 0 estudo mais detalhado desses modelos pode auxiliar na investigação e na tomada de decisões dos investidores ou doadores sobre qual modelo apoiar, como apoiar e como avaliar o desempenho. Esses modelos podem ser identificados com base nas formas de capital, como político, humano, econômico e social, podendo estar combinadas em um mesmo negócio ou não. Os modelos que alavancam o capital econômico merecem atenção (MAIR; BATTILANA; CARDENAS, 2012). Os investidores esperam que a empresa social use os fundos para aumentar o retorno financeiro e/ou o impacto social, no entanto, melhorar rentabilidade e expandir operações sem comprometer 


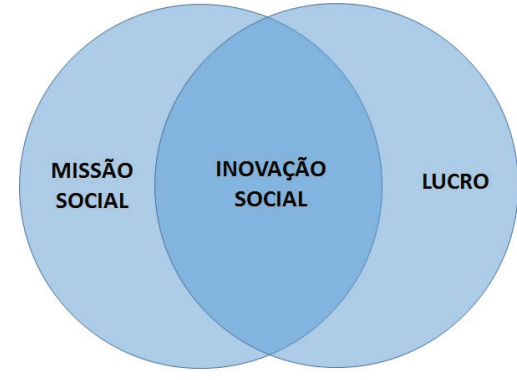

Inovação social pode congregar missão social e resultado econômico para alguns autores.

Fonte: Elaborada pelas autoras com base na pesquisa realizada.

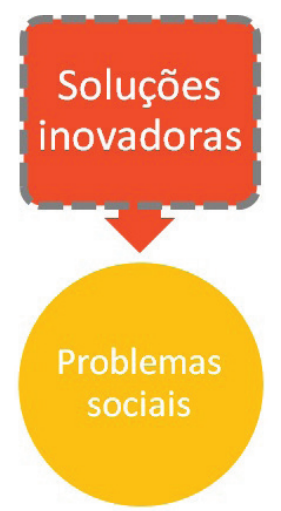

Papel distintivo do empreendedorismo social: explorar soluções inovadoras para problemas sociais.

Fonte: Elaborada pelas autoras com base na pesquisa realizada. a missão é uma tarefa difícil. A avaliação do impacto social e as medidas de desempenho são ferramentas que podem apoiar as iniciativas de empreendedorismo e inovação social a alcançarem resultados financeiros sem pôr em risco sua missão social (MAIR; SHARMA, 2012).

A maioria das definições tanto de inovação social como de empreendedorismo social focam na criação de valor social como a principal missão de suas atividades, no entanto, alguns autores sugerem que os resultados econômicos fazem parte da missão social. Na realidade, 0 valor econômico tem grande importância para a sustentabilidade dos empreendimentos sociais e a criação de valor social (DANCIN; DANCIN, 2011). Assim, é difícil dissociar a criação de valor social do resultado econômico, podendo, entretanto, existir uma ordem hierárquica de prioridade entre eles (DANCIN; DANCIN; MATEAR, 2010). Dessa forma, o foco sobre o resultado (positivo ou negativo) dos esforços do empreendedor social incentiva os pesquisadores a examinarem os processos que permitem alcançar tais resultados, estabelecendo o empreendedorismo e a inovação social como um campo de pesquisa (DANCIN; DANCIN, 2011).

Além de criar valor social e gerar resultado econômico, o empreendedorismo social possui um papel distintivo de explorar soluções inovadoras para problemas que foram negligenciados por outros atores institucionais. Os problemas podem ter expressão local, mas com impacto global; e é com essa visão que o empreendedor social se importa em facilitar a divulgação da solução para que outros possam adotá-la também. Por isso o empreendedorismo social é definido como um processo de inovação econômica, que pode surpreender nossas expectativas sobre o comportamento humano, a ação econômica e o próprio papel do empreendedorismo social (SANTOS, 2012).

A teoria tradicional dos negócios criou um ser humano unidimensional que só se preocupa com a maximização do lucro. No entanto, isso não é real, pois as pessoas possuem emoções, crenças, prioridades e comportamentos, e nem todo negócio precisa ter o único objetivo de maximização do lucro (YUNUS, 2008). Por exemplo, a compaixão é uma característica do ser humano que, segundo Miller et al. (2012), aumenta a probabilidade de as pessoas se envolverem em empreendedorismo social, provocando uma motivação pró-social que promove processos de pensamentos mais flexíveis e maior compromisso com a ação. 
Além da motivação social, os empreendimentos sociais necessitam de meios para mobilizar a ação através das fronteiras e escalas do sistema social. As redes sociais podem desempenhar um papel fundamental na difusão da mudança sustentável, funcionando como os meios condutores para a mobilização rápida e a transferência de conhecimento na inovação social (MOORE; WESTLEY, 2011). Coalizões e redes têm sido consideradas a chave para a mudança bem-sucedida, o agente essencial da inovação em qualquer tipo de negócio, e, no caso da inovação social, podem ser mais amplas, interligando comissários do setor público, investidores, defensores de movimentos sociais e empresários de negócios convencionais (MURRAY; CAULIER-GRICE; MULGAN, 2010). Muitos estudos têm sido desenvolvidos relacionando a velocidade de difusão com a estrutura da rede. Young (2011) modela a dinâmica da inovação social como um jogo de coordenação jogado em rede. Ele defende que a taxa com que a inovação social se espalha depende de três fatores: o ganho da inovação em relação ao status quo, a capacidade de resposta ou racionalidade dos agentes, ou a quantidade de ruído no melhor processo de resposta, e a topologia da rede, isto é, a presença de pequenos enclaves autônomos, como grupos locais, onde a inovação pode ganhar uma posição inicial.

Foi observado em muitos estudos que a diferenciação entre a inovação social e o empreendedorismo social não tem tanta relevância como suas dimensões semelhantes. Clautier (2003) distingue quatro dimensões de análise da inovação social: sua natureza ou objetivo; seu processo de criação; o alvo de mudança; e os resultados obtidos. Diversas pesquisas focam na natureza da inovação social e sua missão. Alguns estudos compreendem inovação social como um processo e realizam pesquisas para melhorá-lo. As mudanças e as melhorias individuais e locais causadas pela inovação social também são universos interessantes de análise. No entanto, dentre o universo de pesquisas sobre inovação social e empreendedorismo social, poucas têm abordado a questão dos resultados duradouros obtidos. A avaliação de impacto social e as medidas de desempenho, além de servirem para realizar a prestação de contas a investidores, doadores e colaboradores internos e externos, são importantes ferramentas de apoio às iniciativas sociais (MAIR; SHARMA, 2012) e têm sido alvo de recentes pesquisas, mas carecem de maiores desdobramentos.

As definições encontradas na literatura pesquisada para empreendedorismo social e inovação social estão representadas no Quadro 3.

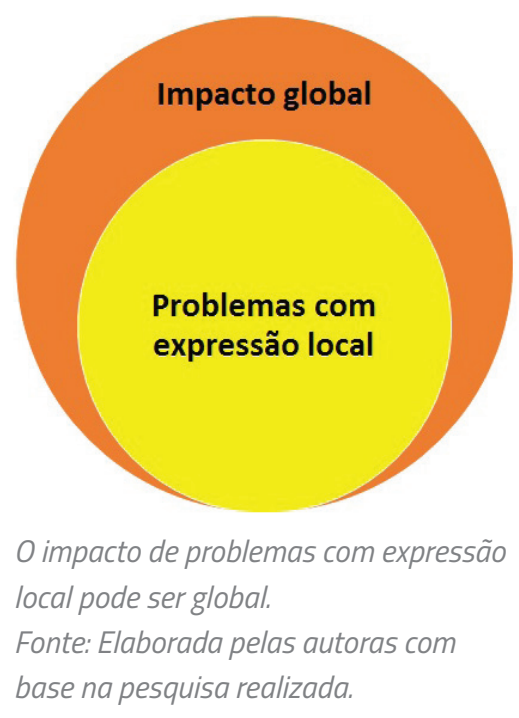

base na pesquisa realizada. 
Quadro 3 Definições dos construtos.

\begin{tabular}{|c|c|c|}
\hline Autor (Ano) & Inovação social & Empreendedorismo social \\
\hline $\begin{array}{l}\text { Dacin, Dacin } \\
\text { e Tracey } \\
(2011)\end{array}$ & $\begin{array}{l}\text { Os autores não se } \\
\text { preocupam em fazer a } \\
\text { definição de inovação } \\
\text { social, mas afirmam que, } \\
\text { para introduzir a mudança } \\
\text { social, os empreendedores } \\
\text { sociais criam inovações }\end{array}$ & $\begin{array}{l}\text { Fornece soluções para } \\
\text { problemas sociais } \\
\text { equilibrando dois conjuntos } \\
\text { de prioridades: a criação de } \\
\text { valor social e o resultado } \\
\text { econômico. }\end{array}$ \\
\hline $\begin{array}{l}\text { Santos } \\
(2012)\end{array}$ & $\begin{array}{l}\text { Não define inovação } \\
\text { social. Considera que os } \\
\text { empreendedores sociais } \\
\text { criam soluções práticas e } \\
\text { inovadoras para criar valor } \\
\text { para a sociedade }\end{array}$ & $\begin{array}{l}\text { É um processo de inovação } \\
\text { na economia que pode } \\
\text { acontecer em diferentes } \\
\text { contextos institucionais, } \\
\text { baseia-se na criação de } \\
\text { valor, desenvolvendo } \\
\text { soluções sustentáveis para } \\
\text { os problemas sociais, e } \\
\text { opera por suas próprias } \\
\text { regras e lógica }\end{array}$ \\
\hline $\begin{array}{l}\text { Miller et al. } \\
\text { (2012) }\end{array}$ & $\begin{array}{l}\text { Não define inovação } \\
\text { social; sugere que o } \\
\text { empreendedorismo social } \\
\text { pode gerar algum tipo de } \\
\text { atividade inovadora de } \\
\text { mercado, distribuição, } \\
\text { processo ou fluxo de } \\
\text { receita }\end{array}$ & $\begin{array}{l}\text { É o processo de } \\
\text { inicialização de uma forma } \\
\text { organizacional híbrida que } \\
\text { cria valor social por meio } \\
\text { de métodos baseados no } \\
\text { mercado }\end{array}$ \\
\hline $\begin{array}{l}\text { Moore e } \\
\text { Westley } \\
(2011)\end{array}$ & $\begin{array}{l}\text { É toda iniciativa, produto, } \\
\text { processo ou programa } \\
\text { que muda rotinas básicas, } \\
\text { recursos e fluxos de } \\
\text { autoridade ou crenças de } \\
\text { qualquer sistema social }\end{array}$ & $\begin{array}{l}\text { Tipo de empreendedorismo } \\
\text { considerado no } \\
\text { entendimento de inovações } \\
\text { sociais e seu impacto na } \\
\text { resiliência, que é o inventor } \\
\text { de uma nova norma, ideia } \\
\text { ou produto }\end{array}$ \\
\hline
\end{tabular}




\begin{tabular}{|c|c|c|}
\hline Autor (Ano) & Inovação social & Empreendedorismo social \\
\hline $\begin{array}{l}\text { Young } \\
(2011)\end{array}$ & $\begin{array}{l}\text { Um novo mecanismo que } \\
\text { aumenta o bem-estar dos } \\
\text { indivíduos que o adotam } \\
\text { comparado com o estado } \\
\text { em que estavam }\end{array}$ & $\begin{array}{l}\text { Não define } \\
\text { empreendedorismo social }\end{array}$ \\
\hline $\begin{array}{l}\text { Bacq e } \\
\text { Janssen } \\
\text { (2011) }\end{array}$ & $\begin{array}{l}\text { Não define a inovação } \\
\text { social, porém define o } \\
\text { empreendedor social } \\
\text { como um indivíduo } \\
\text { visionário capaz de } \\
\text { encontrar soluções } \\
\text { inovadoras }\end{array}$ & $\begin{array}{l}\text { É o processo de } \\
\text { identificação, avaliação } \\
\text { e exploração de } \\
\text { oportunidades que visam } \\
\text { à criação de valor social } \\
\text { por meio de atividades } \\
\text { comerciais, com base no } \\
\text { mercado, e da utilização } \\
\text { de uma vasta gama de } \\
\text { recursos }\end{array}$ \\
\hline $\begin{array}{l}\text { Mair et al. } \\
\text { (2012) }\end{array}$ & Não define inovação social & $\begin{array}{l}\text { O objetivo dos } \\
\text { empreendedores sociais é } \\
\text { alcançar a missão social que } \\
\text { perseguem }\end{array}$ \\
\hline $\begin{array}{l}\text { Cajaiba- } \\
\text { Santana } \\
(2014)\end{array}$ & $\begin{array}{l}\text { São novas práticas criadas } \\
\text { a partir de ações coletivas, } \\
\text { intencionais e orientadas } \\
\text { por objetivos, destinadas } \\
\text { a levar mudança social por } \\
\text { meio da reconfiguração de } \\
\text { como objetivos sociais são } \\
\text { atingidos }\end{array}$ & $\begin{array}{l}\text { É uma perspectiva da } \\
\text { inovação social que valoriza } \\
\text { o indivíduo, seguindo a } \\
\text { linha schumpeteriana de } \\
\text { empreendedores heróis }\end{array}$ \\
\hline $\begin{array}{l}\text { Witkamp et } \\
\text { al. (2011) }\end{array}$ & $\begin{array}{l}\text { Não faz diferença } \\
\text { entre os conceitos } \\
\text { de inovação social e } \\
\text { empreendedorismo social }\end{array}$ & $\begin{array}{l}\text { É um novo modelo de } \\
\text { negócio que combina um } \\
\text { objetivo social com uma } \\
\text { mentalidade empresarial, e, } \\
\text { assim, é considerado uma } \\
\text { importante forma de criar } \\
\text { valor social }\end{array}$ \\
\hline
\end{tabular}




\begin{tabular}{|c|c|c|}
\hline Autor & Inovação social & Empreendedorismo social \\
\hline $\begin{array}{l}\text { Maclean et } \\
\text { al. (2013) }\end{array}$ & $\begin{array}{l}\text { Uma inovação é chamada } \\
\text { de inovação social se a } \\
\text { nova ideia implícita tem o } \\
\text { potencial para melhorar } \\
\text { qualidade ou quantidade } \\
\text { de vida; inovação social é, } \\
\text { potencialmente, mudança } \\
\text { do sistema }\end{array}$ & $\begin{array}{l}\text { Declara que os conceitos } \\
\text { de inovação social e } \\
\text { empreendedorismo social } \\
\text { estão intimamente ligados, } \\
\text { com a pressão para inovar } \\
\text { sendo parte integrante do } \\
\text { empreendedorismo social }\end{array}$ \\
\hline $\begin{array}{l}\text { Chalmers } \\
\text { (2013) }\end{array}$ & $\begin{array}{l}\text { São definidas como } \\
\text { novas ideias que } \\
\text { simultaneamente } \\
\text { atendem às necessidades } \\
\text { sociais e criam novas } \\
\text { relações ou colaborações } \\
\text { sociais (MURRAY, 2010) }\end{array}$ & $\begin{array}{l}\text { Empreendedorismo social } \\
\text { tende a concentrar-se sobre } \\
\text { o indivíduo que impulsiona a } \\
\text { mudança social }\end{array}$ \\
\hline $\begin{array}{l}\text { Shaw e De } \\
\text { Bruin (2013) }\end{array}$ & $\begin{array}{l}\text { Sugere que os focos de } \\
\text { investigações sejam } \\
\text { desviados de fazer } \\
\text { considerações sobre } \\
\text { as definições para } \\
\text { fazer interações entre } \\
\text { a inovação social e o } \\
\text { empreendedorismo social }\end{array}$ & $\begin{array}{l}\text { Envolve processos, } \\
\text { atividades e } \\
\text { comportamentos } \\
\text { convencionais para produzir } \\
\text { um ganho distinto das } \\
\text { empresas tradicionais, } \\
\text { ou seja, para atender às } \\
\text { necessidades sociais, } \\
\text { ambientais e educacionais }\end{array}$ \\
\hline $\begin{array}{l}\text { Smith e } \\
\text { Woodworth } \\
(2012)\end{array}$ & $\begin{array}{l}\text { Não diferencia } \\
\text { inovação social de } \\
\text { empreendedorismo social; } \\
\text { o empreendedorismo } \\
\text { social, visto como um } \\
\text { processo, pode envolver } \\
\text { a oferta de novo serviço, } \\
\text { produto ou a criação de } \\
\text { nova organização }\end{array}$ & $\begin{array}{l}\text { É um processo que } \\
\text { combina recursos de novas } \\
\text { formas, destinando-se } \\
\text { principalmente à exploração } \\
\text { e ao aproveitamento de } \\
\text { oportunidades para criar } \\
\text { valor social, estimulando } \\
\text { a mudança social ou a } \\
\text { satisfação de necessidades } \\
\text { sociais }\end{array}$ \\
\hline
\end{tabular}




\begin{tabular}{|c|c|c|}
\hline Autor (Ano) & Inovação social & Empreendedorismo social \\
\hline $\begin{array}{l}\text { Phillips et al. } \\
\text { (2015) }\end{array}$ & $\begin{array}{l}\text { É uma nova solução para } \\
\text { um problema social que } \\
\text { é mais eficaz, ou apenas } \\
\text { eficiente, que as soluções } \\
\text { existentes, criando } \\
\text { valor para a sociedade } \\
\text { como um todo (PHILLS; } \\
\text { DEIGLMEIER; MILLER, } \\
\text { 2008) }\end{array}$ & $\begin{array}{l}\text { Como a inovação social, } \\
\text { está relacionado com } \\
\text { a identificação de uma } \\
\text { oportunidade de resolução } \\
\text { de problemas para atender } \\
\text { a uma necessidade social, } \\
\text { perseguindo, assim, uma } \\
\text { missão social }\end{array}$ \\
\hline $\begin{array}{l}\text { Nandan et } \\
\text { al. (2015) }\end{array}$ & $\begin{array}{l}\text { Inclui quaisquer novos } \\
\text { processos, produtos e } \\
\text { serviços que tratem de } \\
\text { questões sociais, para } \\
\text { melhorar a qualidade de } \\
\text { vida humana nos níveis } \\
\text { micro e macro (POL; VILLE, } \\
\text { 2009) }\end{array}$ & $\begin{array}{l}\text { É o estabelecimento de } \\
\text { iniciativas para implementar } \\
\text { inovações sociais; usam a } \\
\text { inovação para criar valor e } \\
\text { mudança social por meio de } \\
\text { um novo empreendimento } \\
\text { (SCHMITZ; SCHEUERLE, } \\
\text { 2012) }\end{array}$ \\
\hline $\begin{array}{l}\text { Cunha et al. } \\
\text { (2015) }\end{array}$ & $\begin{array}{l}\text { É a mudança de } \\
\text { sistemas por meio do } \\
\text { desenvolvimento de } \\
\text { soluções inovadoras, } \\
\text { abrangendo comunidades } \\
\text { de aprendizagem } \\
\text { para criar valor } \\
\text { social e promover o } \\
\text { desenvolvimento da } \\
\text { comunidade, desafiando } \\
\text { as instituições sociais } \\
\text { existentes pelo } \\
\text { desenvolvimento da ação } \\
\text { colaborativa de redes mais } \\
\text { amplas (CLOUTIER, 2003) }\end{array}$ & $\begin{array}{l}\text { É um campo de ação } \\
\text { envolvendo diferentes } \\
\text { tipos de atores, em que } \\
\text { contextos socioculturais } \\
\text { e históricos surgem como } \\
\text { principais características } \\
\text { e os indivíduos, os } \\
\text { empreendedores sociais, } \\
\text { constroem resultados, } \\
\text { por meio de agilidade } \\
\text { empresarial e motivação } \\
\text { para resolver problemas } \\
\text { sociais }\end{array}$ \\
\hline
\end{tabular}

Fonte: Elaborado pelas autoras. 


\section{CONSIDERAÇÕES FINAIS}

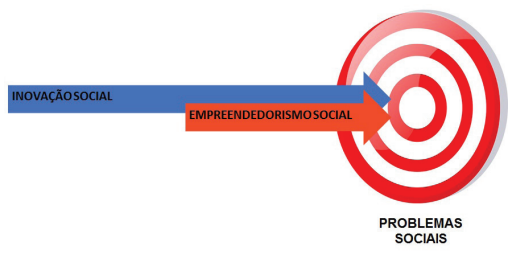

Alvo comum da inovação social e do empreendedorismo social: resolver problemas sociais. Fonte: Elaborada pelas autoras com base na pesquisa realizada.
Cumprindo a sequência metodológica proposta, este artigo definiu como objetivo a análise da produção científica sobre a inovação social e o empreendedorismo social e como critério de exclusão e inclusão a produção dos artigos entre 2011 e 2016. A revisão integrativa propiciou a seleção de uma amostra dos artigos mais citados na base de dados Scopus; os artigos selecionados foram apresentados e categorizados no Quadro 2. A análise dos resultados aponta para um grande aumento na produção científica nos últimos anos, fato de extrema importância dada a relevância do tema.

Foi possivel notar que existem artigos preocupados em fazer a distinção entre os dois construtos, no entanto, esse tipo de discussão não traz resultados importantes para a evolução do campo de pesquisas de inovação social e empreendedorismo social. Por isso, outros estudos nem se empenham em fazer a diferenciação dos termos, mas em analisar suas dimensões semelhantes. Assim, nota-se que, entre as definições de inovação social e empreendedorismo social existentes, o objetivo principal é criar valor social, perseguindo a missão social.

No entanto, estudos recentes abordam o retorno financeiro como um possível componente da inovação social. Isso significa dizer que o empreendimento social pode manter a sua missão social e ao mesmo tempo ser autossustentável, além disso, como as empresas tradicionais, deve avaliar e demonstrar seu desempenho para atrair novos investidores e manter as parcerias já existentes. Dessa forma, é possível que a inovação social consiga ainda aumentar o seu valor social a partir da geração de lucro. Apesar de alguns pesquisadores alertarem que ter uma abordagem dupla de resultados, valor social e retorno financeiro, pode comprometer a principal característica da inovação social, estudos precisam ser desenvolvidos para entender quais são os fatores que permitem que a empresa permaneça comprometida com sua missão social (MAIR; BATTILANA; CARDENAS, 2012).

A perspectiva do empreendedor social como figura central do empreendedorismo social também é registrada como uma questão preponderante para entendimento das atividades com impacto social. A visão schumpeteriana do empreendedor herói (SMELSER; SWEDBERG, 
2010) valoriza o indivíduo como ator principal do empreendedorismo social, entretanto, essa ideia não é aceita em todas as escolas de inovação social. A formação de parcerias e redes tem sido considerada a ferramenta-chave para a inovação social bem-sucedida.

Dessa forma, foi possivel atingir o objetivo deste estudo, ampliandose o conhecimento sobre a produção acadêmica relativa à inovação social e ao empreendedorismo social. A síntese do levantamento da literatura existente vislumbrou algumas características importantes dos construtos e suas dimensões semelhantes, demonstrando não apenas a relevância do tema, mas a necessidade de novos estudos e aprofundamento dessa temática.

\section{REFERÊNCIAS}

AUSTIN, J.; STEVENSON, H.; WEI-SKILLERN, J. Social and commercial entrepreneurship: same, different, or both? Entrepreneurship theory and practice, v. 30, n. 1, p. 1-22, 2006

BACQ, S.; JANSSEN, F. The multiple faces of social entrepreneurship: a review of definitional issues based on geographical and thematic criteria. Entrepreneurship and Regional Development, v. 23, п. 5-6, p. 373-403, 2011.

BECK, C. T. (Ed.). Essentials of nursing research: methods, appraisal and utilization. Philadelphia: Lippincott Williams \& Wilkins, 2006.

BOTELHO, L. L. R.; CUNHA, C. C. A.; MACEDO, M. O método da revisão integrativa nos estudos organizacionais. Revista Eletrônica Gestão e Sociedade, Belo Horizonte, v. 5, n. 11, p. 121-136, maio/ago. 2011.

CAJAIBA-SANTANA, G. Social innovation: Moving the field forward: a conceptual framework. Technological Forecasting and Social Change, v. 82, n. 1, p. 42-51, 2014

CHALMERS, D. Social innovation: An exploration of the barriers faced by innovating organizations in the social economy. Local Economy, v. 28, n. 1, p. 17-34, 2013.

CLOUTIER, J. Qu'est-ce que l'innovation sociale? Quebec: CRISES, 2003.

CUNHA, J.; BENNEWORTH, P.; OLIVEIRA, P. Social entrepreneurship and social innovation: A conceptual distinction. Handbook of research on global competitive advantage through innovation and entrepreneurship, p. 616-639, 2015.

DACIN, M. T.; DACIN, P. A.; TRACEY, P. Social entrepreneurship: A critique and future directions. Organization Science, v. 22, n. 5, p. 1203-1213, 2011

DACIN, P. A.; DACIN, M. T.; MATEAR, M. Do we need a theory of social entrepreneurship? Academy of Management Perspect. v. 24, n. 3, p. 37-57, 2010

JULIANI, D. P. Framework da Cultura Organizacional nas Universidades para a Inovação Social [tese]. Florianópolis: Universidade Federal de Santa Catarina, Programa de Pós-graduação em Engenharia e Gestão do Conhecimento, 2015. 
MACLEAN, M.; HARVEY, C.; GORDON, J. Social innovation, social entrepreneurship and the practice of contemporary entrepreneurial philanthropy. International Small Business Journal, v. 31, n. 7, p. 747-763, 2013

MAIR, J.; BATTILANA, J.; CARDENAS, J. Organizing for society: A typology of social entrepreneuring models. Journal of Business Ethics, v. 111, n. 3, p. 353-373, 2012.

MAIR, J.; SHARMA, S. Performance Measurement and Social Entrepreneurship. In: VOLKMANN, C. K.; TOKARSKI, K. O.; ERNST, K. (Eds.). Social Entrepreneurship and Social Business: an introduction and discussion with case studies. Wiesbaden: Springer Gabler, 2012. p. 175-189.

MILLER, T. L.; GRIMES, M. G.; MCMULLEN, J. S.; VOGUS, T. J. Venturing for others with heart and head: How compassion encourages social entrepreneurship. Academy of Management Review, v. 37, n. 4, p. 616-640, 2012.

MOORE, M.-L.; WESTLEY, F. Surmountable chasms: Networks and social innovation for resilient systems. Ecology and Society, v. 16, n. 1, 2011 [online].

MULGAN, G.; TUCKER, S; ALI, R; SANDERS, B. Social Innovation: what it is, why it matters and how it can be accelerated. Oxford: Oxford Said Business School - Skoll Centre for Social Entrepreneurship, 2007

MURRAY, R.; CAULIER-GRICE, J.; MULGAN, G. The Open Book of Social Innovation. London: NESTA/The Young Foundation, 2010. Disponivel em: <www.nesta.org.uk/publications/assets/ features/the_open_book_of_social_innovation>. Acesso em: 11 jun. 2016.

NANDAN, M.; LONDON, M.; BENT-GOODLEY, T. Social workers as social change agents: Social innovation, social intrapreneurship, and social entrepreneurship. Human Service Organizations Management, Leadership and Governance, v. 39, n. 1, p. 38-56, 2015.

ORGANIZAÇÃO PARA A COOPERAÇÃO E DESENVOLVIMENTO ECONÔMICO - OCDE. Manual de Oslo: proposta de ações de intervenção para coleta e interpretação de dados sobre inovação tecnológica. 3. ed. Brasilia: FINEP, 2005

PHILLIPS, W., LEE, H., GHOBADIAN, A., O'REGAN, N., JAMES, P. Social innovation and social entrepreneurship: A systematic review. Group and Organization Management, v. 40, n. 3, p. 428$-461,2015$

PHILLS, J. A.; DEIGLMEIER, K.; MILLER, D. T. Rediscovering social innovation. Stanford Social Innovation Review, v. 6, p. 34-43, 2008

POL, E.; VILLE, S. Social innovation: Buzz word or enduring term? The Journal of Socio-Economics, v. 38, p. $878-885,2009$

POLIT, D. F; BECK, C. T. Using research in evidence-based nursing practice. In: (Ed.) Essentials of nursing research. Methods, appraisal and utilization. Philadelphia: Lippincott Williams \& Wilkins, 2006.

PORTER, M. E. Competitive strategy techniques for analysing industries and competitors. New York: Free Press, 1980.

SANTOS, F. M. A positive theory of social entrepreneurship. Journal of Business Ethics, v. 111, n. 3, p. 335-351, 2012.

SCHMITZ, B.; SCHEUERLE, T. Founding or transforming? Social intrapreneurship in three German Christian-based NPOs. ACRN Journal of Entrepreneurship Perspectives, v. 1, n. 1, p. 13$-36,2012$

SCHUMPETER, J. O fenômeno fundamental do desenvolvimento econômico. In: A Teoria do Desenvolvimento Econômico. Rio de Janeiro: Nova Cultural, 1985

SHAW, E.; DE BRUIN, A. Reconsidering capitalism: The promise of social innovation and social entrepreneurship? International Small Business Journal, v. 31, n. 7, p. 737-746, 2013. 
SMELSER, N.; SWEDBERG, R. (Ed.). The handbook of economic sociology. Princeton: Princeton University Press, 2010.

SMITH, I. H.; WOODWORTH, W. P. Developing social entrepreneurs and social innovators: A social identity and self-efficacy approach. Academy of Management Learning and Education, v. 11, n. 3, p. 390-407, 2012.

WHITTEMORE, R.; KNAFL, K. The integrative review: updated methodology. Journal of Advanced Nursing, Oxford, v. 52, n. 5, p. 546-553, 2005

WITKAMP, M. J.; RAVEN, R. P. J. M.; ROYAKKERS, L. M. M. Strategic niche management of social innovations: The case of social entrepreneurship. Technology Analysis and Strategic Management, v. 23, n. 6, p. 667-681, 2011.

YOUNG, H. P. The dynamics of social innovation. Proceedings of the National Academy of Sciences of the United States of America, v. 108, s. 4, p. 21285-21291, 2011.

YUNUS, M. Creating a World Without Poverty: Social Business and the Future of Capitalism. Global Urban Development. v. 4, n. 2, 2008. 
